УДК 621.436

ПОДХОДЫ К ОЦЕНКЕ ТОПЛИВ ДЛЯ ГИПЕРЗВУКОВЫХ ДВИГАТЕЛЕЙ

\author{
(C) 2013 С. М. Сергеев, Н. В. Петрухин
}

ФАУ «25 ГосНИИ химмотологии Минобороны России», г. Москва

\begin{abstract}
Представлены полученные при помощи многоцелевого программного комплекса параметры газового потока в четырёх сечениях двигателя для скорости полета $8 \mathrm{M}$ на высоте 20 км для различных углеводородных топлив. Анализ полученных результатов позволил определить уровень требований к основным свойствам горючих, оценить возможность применения различных углеводородных топлив для ГПВРД, обосновать необходимость разработки нового топлива для ГПВРД, а также новых методов оценки его горючести.
\end{abstract}

Гиперзвуковые летательные аппараты, горение в сверхзвуковом потоке, требования к топливам, углеводородное горючее, жидкое ракетное гиперзвуковое топливо, комплекс методов.

Гиперзвуковые летательные аппараты (ГЛА) - класс летательных аппаратов (ЛА), обладающих свойствами как авиационных, так и космических аппаратов, способных совершать орбитальный полёт в околоземном космическом пространстве и маневрировать в атмосфере с использованием аэродинамических сил. Реализация преимуществ ГЛА сопряжена с решением проблемных химмотологических вопросов: организация горения в сверхзвуковом потоке, обеспечение высокой тяги, охлаждение конструкции двигателя, устойчивое сгорание горючего в камере сгорания и других, непосредственно связанных с составом (свойствами) топлива.

Для оценки возможностей топлив в условиях гиперзвукового ВРД, работающего по схеме с торможением приходящего воздуха до звуковой скорости, расчётным методом с использованием многоцелевого программо-аппаратного комплекса, разработанного МГТУ им. Баумана «Астра. 4/pc*» [1], были получены параметры газового потока в четырёх сечениях двигателя: на входе в воздухозаборник, на входе в камеру сгорания, на выходе из неё и на срезе сопла. В качестве исходных данных для расчётов были выбраны следующие условие полёта ЛА: скорость $-8 \mathrm{M}$, высота - 20 км.

Выполненный анализ позволил сформулировать основные требования к топливу для ГПВРД.
Требования по энергомассовым характеристикам топлив оцениваются двумя свойствами: их плотностью и удельным импульсом тяги.

Дальность полёта ГЛА непосредственно связана с плотностью топлива.

Плотность горючего, кроме влияния на увеличение дальности полёта при равенстве других показателей энергозапаса на борту ЛА, для ГПВРД имеет дополнительное важное значение. Повышенная величина плотности позволяет уменьшать размеры ЛА, улучшать аэродинамические характеристики, в частности коэффициент подъёма $\Omega$ (рис. 1) [2] и, в конечном счёте, сокращать затраты на охлаждение двигателя и ЛА в целом.

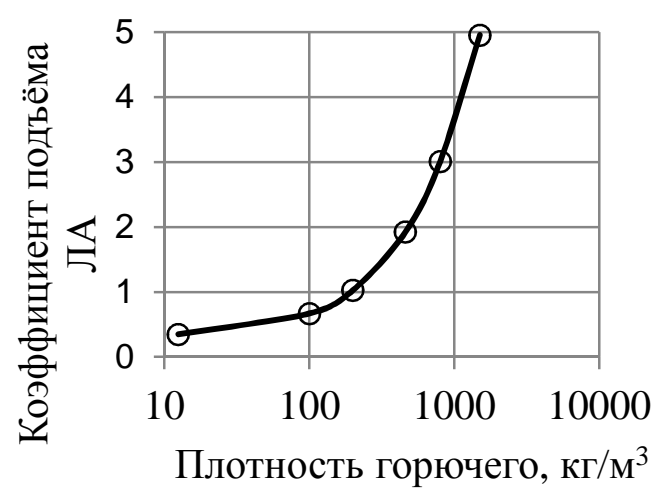

Рис. 1. Зависимость коэффициента подъёма ЛА от плотности горючего 
Известно, что соотношение теплот сгорания топлив не соответствует такому же соотношению их удельных импульсов тяги. Так, теплота сгорания жидкого водорода почти в три раза превышает теплоту сгорания углеводородных топлив, в то время как по удельному импульсу они отличаются лишь в 1,26 - 1,14 раза.

Таким образом, криогенные горючие, выигрывая в величине удельного импульса тяги, значительно уступают по плотности. Это суммарно подтверждается расчётными данными по разности в баллистической эффективности, представленной в табл. 1, в сравнении с жидким водородом.

Охлаждение ГПВРД является одной из основных трудностей при освоении гиперзвука. Оценка охлаждающих свойств топлива проводилась по его хладоресурсу [3], который характеризует потенциальную возможность топлива поглощать тепло при использовании его в качестве охлаждающей среды в двигателе. По величине хладоресурса и топливного потока в камере сгорания и сопловом блоке получены максимальные скорости полёта ЛА, на которых вероятно достижение термостабильности корпуса двигателя: углеводородные горючие - до 6М, сжиженный метан - до 8М и шугообразный водород - до 10М и выше.

Важными являются также требования по обеспечению устойчивого сверхзвукового горения топлива. Обеспечение устойчивого сверхзвукового горения для ГПВРД осложняется сравнительно низким давлением топливной смеси в камере сгорания 40 - 80 кПа. Достижение устойчивости горения может быть обеспечено, кроме конструктивных особенностей двигателя, высокой скоростью сгорания топлива, его теплофизическими свойствами (температуропроводность, скорость диффузии, испаряемость и др.).

Анализ полученных расчётных и экспериментальных результатов позволил определить уровень требований к основным свойствам топлив (табл. 2).

Таблица 1. Сравнительная оценка баллистической эффективности углеводородных горючих по отношению к жидкому $\mathrm{H}_{2}$ при $V_{\text {запр. }}=$ const

\begin{tabular}{|l|c|c|c|}
\hline \multirow{2}{*}{ Класс летательных аппаратов } & \multicolumn{3}{|c|}{ Дальность, км } \\
\cline { 2 - 4 } & жидкий $\mathrm{H}_{2}$ & JP-10 & T-1. JP-7 \\
\hline Тактический & 400 & 680 & 620 \\
\hline Оперативно-тактический & 1000 & 1300 & 1230 \\
\hline Средней дальности & 3000 & 7650 & 6670 \\
\hline
\end{tabular}

Таблица 2. Уровень требований к топливам для ГПВРД и некоторые их значения

\begin{tabular}{|c|c|c|c|c|c|c|c|}
\hline Характеристика топлива & $\begin{array}{c}\text { Требования } \\
\text { к топливу } \\
\text { для ГЛА }\end{array}$ & $\begin{array}{l}\mathrm{H}_{2} \\
\text { (Ж) }\end{array}$ & $\begin{array}{c}\mathrm{CH}_{4} \\
(ж)\end{array}$ & $\mathrm{T}-1$ & TC-1 & JP-10 & JP-7 \\
\hline 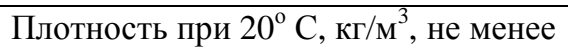 & 960 & $71-82$ & 424 & 833 & 780 & 938 & 790 \\
\hline Удельная энергия, МДж/л & $\geq 41,3$ & $8,2-9,3$ & 20,8 & 35,8 & 33,6 & 40,4 & 34,7 \\
\hline Относительная дальность полёта & $\geq 1,5$ & 1,0 & 1,15 & 1,24 & 1,23 & 1,4 & 1,25 \\
\hline Время сгорания топлива, мс & $<3$ & $<3$ & - & - & - & - & - \\
\hline $\begin{array}{l}\text { Допустимая скорость полёта } \\
\text { по хладоресурсу, М }\end{array}$ & $>10$ & $>10$ & 8 & 6 & 6 & 6 & 6 \\
\hline
\end{tabular}


Представленные данные позволяют оценивать возможность использования топлив для реализации их в ГПВРД. Наилучшими энергетическими характеристиками и хорошими охлаждающими свойствами обладают сжиженные водород и метан, однако малая плотность и серьёзные эксплуатационные проблемы не позволяют рассматривать их как основное топливо, особенно для ГЛА военного назначения.

В противоположность жидкому водороду и метану углеводородные топлива имеют более длительный период горения и существенно более низкую энергоотдачу, но гораздо безопаснее, надёжнее и проще в эксплуатации. Их использование в ГЛА позволит получить преимущества в улучшении аэродинамических характеристик. Однако существующие углеводородные топлива - авиационные керосины T-1, TC-1, JP-7 и топливо JP-10 можно использовать только в ГЛА со скоростью полета до 6М (табл. 1).

Анализ возможности применения топлив для ГПВРД показывает, что ни одно из исследованных топлив в полной меpe не удовлетворяет вышеизложенным требованиям. Для обеспечения требований, предъявляемых к ГЛА военного назначения, необходимо разработать топливо, которое позволило бы снять вышеописанные проблемы. Это может быть топливо типа керосинов - жидкое ракетное гиперзвуковое топливо (ЖРГТ) - для сверхзвукового горения в сверхзвуковом потоке воздуха.

Решение этой задачи представляется возможным в двух направлениях:

- разработка нового синтетического углеводородного горючего с улучшенными эксплуатационными свойствами;

- модернизация существующих топлив типа керосинов путём подбора соответствующих присадок и добавок для повышения уровня требуемых эксплуатационных свойств.

Для решения вышеизложенной задачи на первом этапе исследований предла- гается комплекс методов по оценки горючести ЖРГТ:

- метод «Горелка» для исследования горения топлив в условиях ламинарного пламени с целью их ранжирования;

- метод «Пламя» для исследования скоростей сгорания топлив в камере сгорания постоянного объёма;

- метод «Ударная труба» (позволяет моделировать условия гиперзвукового горения) для исследования турбулентного горения топлив в сверхзвуковом потоке.

Предлагаемый комплекс методов позволит оценить топлива по энергетическим характеристикам и влияние присадок на эффективность сгорания; оптимизировать их составы и значительно сократить расходы на проведение испытаний на стендах и натурных объектах.

Таким образом, разработка и обоснование состава жидкого реактивного гиперзвукового топлива представляет раздел химмотологии со специальной экспериментальной базой исследования и теоретическими подходами, включающими термодинамику и кинетику горения в сверхзвуковом воздушном потоке. Внедрение топлив оптимального состава позволит обеспечить эффективность и надежность эксплуатации гиперзвуковых изделий ракетного вооружения и реализовать их преимущества в полном объёме.

\section{Библиографический список}

1. Программа «Астра-4», описание [Текст] / М.: МГТУ им. Н.Э. Баумана, 1996.

2. Mark, J. Lewis Significance of Selection for Hypersonic Vehicle Range [Текст] / J. Mark // Journal of Propulsion and Power. - 2001- Vol. 17, - № 6. - C.12121221.

3. Топлива для воздушнореактивных двигателей [Текст] / Н.Ф. Дубовкин, Л.С. Яновский и др. - М.: МАТИ - Российский государственный технологический университет им. К.Э. Циолковского, 2001. - С. 66-68. 


\title{
APPROACHES TO THE EVALUATION OF FUELS FOR HYPERSONIC ENGINES
}

\author{
(C) 2013 S. M. Sergeev, N. V. Petrukhin
}

25 State Scientific-Research Institute of Chemmotology

of the Russian Ministry of Defense, Moscow

\begin{abstract}
The article presents gas flow parameters in four cross- sections of the engine at the flight speed of $8 \mathrm{M}$ at the altitude of $20 \mathrm{~km}$ for various hydrocarbon fuels. The data were obtained with the use of a multi-purpose program complex. The analysis of the obtained results allowed determining the level of requirements for the basic properties of fuels for hyper-sonic ramjet engines and arguments in favour of developing a new fuel for hypersonic ram-flow jet engines as well as new methods for its evaluation.
\end{abstract}

Hypersonic aircraft, combustion in a supersonic flow, requirements for fuels, hydrocarbon fuel, liquid rocket hypersonic fuelc, complex of methods.

\section{Информация об авторах}

Петрухин Николай Васильевич, доктор технических наук, профессор, ведущий научный сотрудник, ФАУ «25 ГосНИИ химмотологии Минобороны России», г. Москва. E-mail: 25gosniihim@mail.ru. Область научных интересов: физическая химия реактивных топлив.

Сергеев Сергей Михайлович, кандидат технических наук, доцент, начальник лаборатории, ФАУ «25 ГосНИИ химмотологии Минобороны России», г. Москва. Еmail: ssm.58@mail.ru. Область научных интересов: повышение эффективности применения моторных топлив и разработка методов оценки их эксплуатационных свойств.

Petrukhin Nicolay Vasilyevich, Doctor of Science (Engineering), Professor, Chief Researcher, "25 State Scientific and Research Institute of Chemmotology of the Russian Ministry of Defense", Moscow. E-mail: 25gosnihim@mail.ru. Area of research: physical chemistry of jet fuels.

Sergeev Sergey Mikhailovich, Candidate of Science (Engineering), Associate Professor, Head of Laboratory, "25 State Scientific and Research Institute of Chemmotology of the Russian Ministry of Defense”, Moscow. E-mail: ssm.58@ mail.ru. Area of research: increasing the efficiency of using power fuels and methods of assessing their performance characteristics. 